
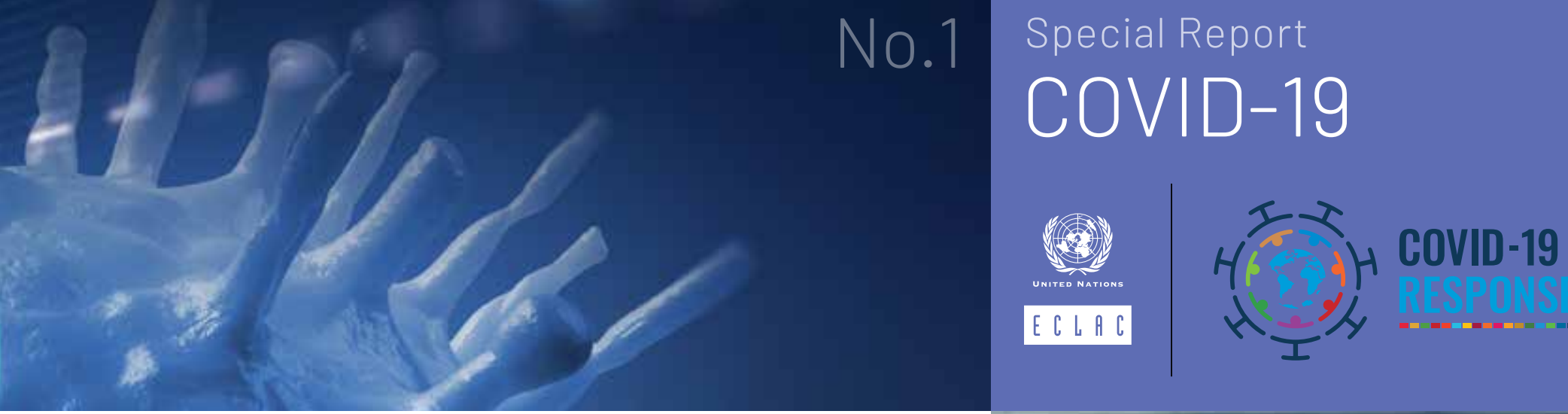

\title{
Latin America and the Caribbean and the COVID-19 pandemic Economic and social effects
}

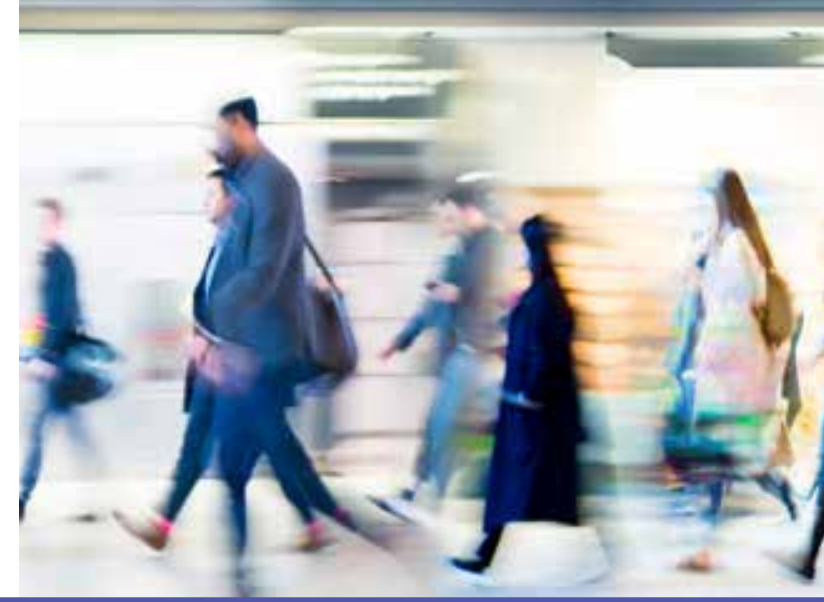

\section{A. Global impact}

- The global economy has been hit by a health, human and economic crisis without precedent in the last century and that is continually evolving. In the face of the coronavirus disease 2019 (COVID-19) pandemic, economies have shut down and are paralyzed, and societies are in quarantine to varying degrees, measures that are only comparable to those in war situations. While it is not known how long the crisis will last or what form the recovery might take, the faster and more robust the response, the fewer negative effects there will be. Some of the traditional market mechanisms may not be sufficient to cope with the crisis owing to the interruption of productive activities and the resulting contraction in demand.

- The State must undertake planning activities to create the conditions needed to sustain and then stimulate supply and demand. This will require public capacities and resources and policy instruments that must be designed in line with the productive capabilities of each country, with the aim of preserving installed capacity. Policy measures to address the crisis are constantly changing, as can be seen in the COVID-19 Observatory in Latin America and the Caribbean of ECLAC, which is updated regularly with this information.

- Beyond any predictive model, government action is being carried out on a trial and error basis. In some cases the health crisis is taking on aspects of a political crisis, as seen in the frequent contradiction between local authorities and central governments or among countries within regional integration blocs. Moreover, the lack of protection for the poorest members of society and the difficulties they face in obtaining basic essential goods has already led to social unrest.

\section{Contents}

A. Global impact 1

B. Impact on Latin America and the Caribbean

1. Economic impact. 5

2. Impact on international trade ......... 6

3. Access to and use of the Internet ... 8

4. Social impacts. 9

5. Policy recommendations .............. 13

Bibliography 14 
COVID-19 will have serious short- and long-term effects on supply and demand at the aggregate and sectoral levels, the intensity and extent of which will depend on domestic conditions of each economy, global trade, how long the epidemic lasts and the social and economic measures taken to prevent its spread (see diagram 1).

Diagram 1 | Economic impacts of the COVID-19 pandemic in Latin America and the Caribbean



Source: Economic Commission for Latin America and the Caribbean (ECLAC).

- The most important action to take in the face of COVID-19 is to contain the spread of the virus through self-isolation, quarantine and social distancing. These measures have positive health impacts by flattening the epidemic curve. However, they also affect economic activity, as social distancing generally implies a slowdown in production or even its total suspension. This reduces working hours and wages and results in a reduction in aggregate demand for goods and services. Since most companies finance their investments largely from retained earnings, gross fixed capital formation will be negatively affected. The multiplier effect of consumption will be decidedly negative and will be exacerbated by the lack of private investment.

The crisis comes at a time when confidence in globalization and multilateralism as tools for development has been deteriorating for more than a decade.

- The 2008 global financial crisis led to a loss of confidence in the ability of markets, in particular the financial market, to ensure stable growth in the absence of regulatory controls and measures.

- Some strategic links in global value chains collapsed after the 2004 Indian Ocean tsunami, which shut down crucial links in the microelectronics components manufacturing chain. Productive activity did not have mechanisms to absorb the effects of this disruption, which were particularly damaging in a context of widespread just-in-time manufacturing.

- The performance of the global economy was already poor before the COVID-19 pandemic. The average global growth rate was $2.8 \%$ for the period 2011-2019, significantly lower than the $3.4 \%$ for the period 1997-2006. In 2019, the global economy recorded its worst performance since 2009, with a growth rate of just $2.5 \%$. Even before the pandemic, global GDP growth projections for 2020 had been revised downwards.

The most optimistic estimates made in the wake of the COVID-19 outbreak predict that global economic growth will decrease to $1.0 \%$ or less. As the pandemic has spread, projections have been revised downward (see figure 1). For example, Goldman Sachs' forecast of 24 March 2020 forecasts annual falls in GDP of 3.8\% in the United States, $9 \%$ in the eurozone and $2.1 \%$ in Japan, and a slowdown in China that would lead to growth of only 3\% (Goldman Sachs, 2020). This is a global recession scenario; moreover, economies could even face a medium-term contraction without the prospect of a rapid recovery. 
Figure 1 | Confirmed cases of COVID-19 worldwide and global growth forecast (Number of cases and percentages)



Source: Bloomberg Economics.

Supply shocks resulting from public health measures adopted to contain the virus depress economic activity (including factory closures, the cessation of operations of some public services and the cancellation of activities and events). Supply chain disruptions may spur cost-push inflation, as demonstrated by the food price hike in China during the outbreak there.

- The magnitude of the aggregate demand shock resulting from reduced consumption of goods and services (including tourism and entertainment services) will depend not only on the measures imposed by governments (quarantines and movement restrictions) but also on the response of individuals and their reaction to the circumstances, particularly with regard to self-isolation and social distancing.

On the financial side, liquidity has been reduced due to the sharp decline in domestic demand, the paralysis of economic activity, disruptions in payment chains, and lost profitability and wealth. In addition, financial market volatility has increased significantly as a result of the uncertainty about the intensity and duration of the pandemic and economic paralysis (see figure 2).

Figure 2 | Financial volatility, November 2018-March 2020

(Volatility indexes)

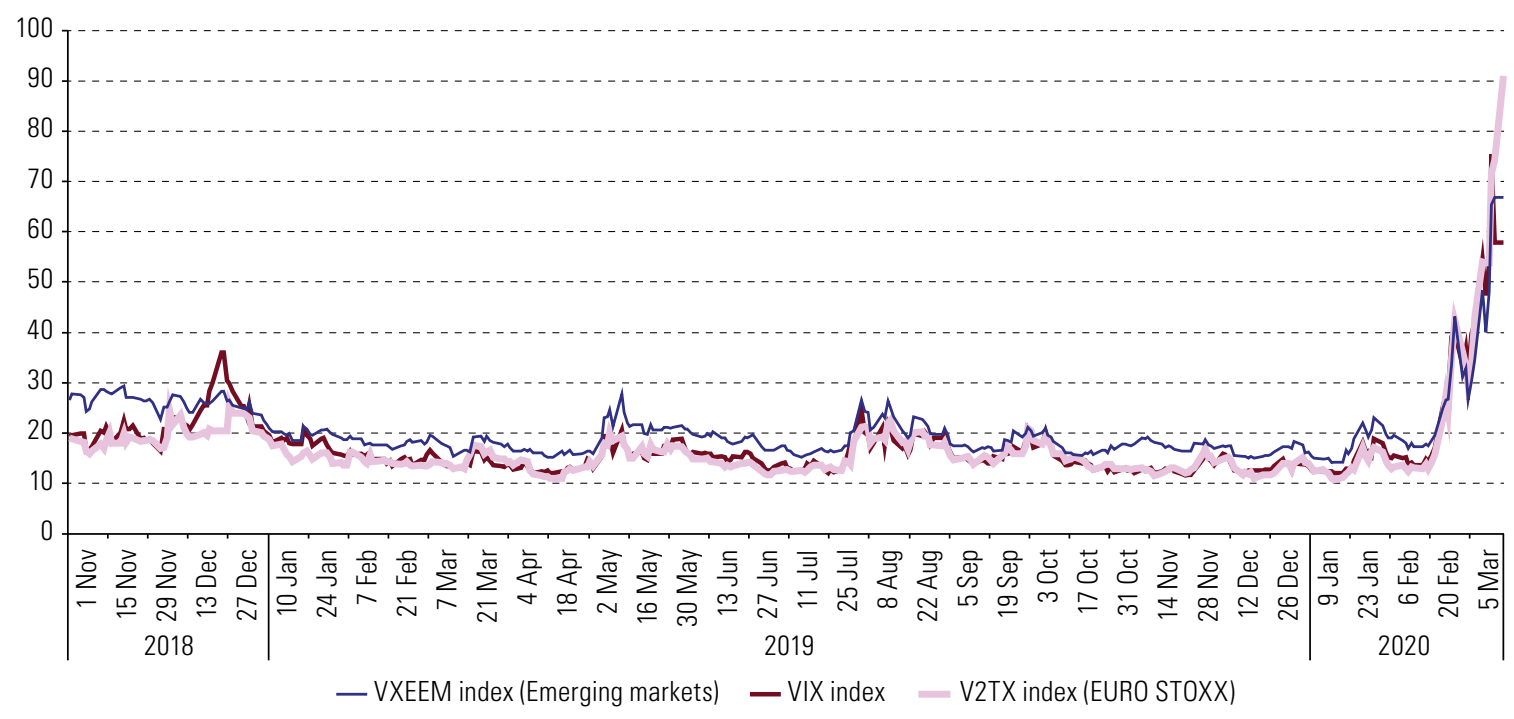

Source:Bloomberg Economics. 
- Liquidity problems have led the United States Federal Reserve to intervene in the overnight bank lending market. The Federal Reserve Board of Governors cut the benchmark interest rate from a target range of $1 \%$ to $1.25 \%$ to one of $0 \%$ to $0.25 \%$. It also announced a US\$ 700 billion quantitative easing programme for the purchase of government bonds and mortgages. Meanwhile, the European Central Bank (ECB) announced measures to support bank lending and expanded its asset purchase programme by 120 billion euros (US $\$ 135.28$ billion). In addition, it launched a 750 billion-euro (US\$ 818.7 billion) stimulus programme for the bond market, which will not be bound by the ECB capital key conditions that limit its ability to buy certain amounts of member States' bonds.

The magnitude of the impact on financial markets is partly explained by vulnerabilities that have been building up for a long time. Debt accumulation has been outpacing global income growth and reached record levels: in the third quarter of 2019, global debt hit US\$253 trillion, or $322 \%$ of global GDP. This mounting debt was accompanied by laxer lending standards and higher risk-taking by investors in their search for yield. Although the upswing in debt occurred across all sectors (households, the non-financial corporate sector, government and the financial sector), what is of greater concern is that much of the debt accumulated since the global financial crisis has been in the non-bank corporate sector. This sector can be severely affected by the disruption of supply chains and the drop in global growth, which means lower earnings and greater difficulties in servicing debt because of disrupted payment chains.

- Global trade was already slowing down before the coronavirus outbreak. The volume of world trade in goods fell by $0.4 \%$ in 2019 , its first drop since the global financial crisis of $2008 / 09$. This was largely the result of the progressive build-up of trade barriers since early 2018 (mainly between the United States and China) and its ripple effect on highly interconnected global value chains.

- Owing to the sharp downward revision of growth for the global economy, it seems increasingly likely that the volume of global trade will contract for a second consecutive year.

- The microeconomic effects will also be very significant.

- Corporate behaviour will continue to shift in the direction of increased nearshoring and confidence in global suppliers will deteriorate. This will result in smaller production batches, loss of economies of scale, scope and learning, and higher production costs. All this will have a negative impact on employment, wages and income distribution.

- All businesses, regardless of size, are affected, especially those in the aviation, tourism and services such as retail. Many are already dealing with a significant decline in revenue, insolvencies and job losses in specific sectors, which will have a considerable impact on the labour market. Sustaining business operations will be particularly difficult for micro-, small and medium-sized enterprises (MSMES) (ILO, 2020).

- The COVID-19 crisis will accelerate some structural changes that began in the last decade. For example, forced quarantine will increase the virtualization of economic and social relations; teleworking will become prevalent in more industries and regions; and digitalization will be fast tracked. In this framework, the most technologically advanced companies will be able to increase their advantages over those companies, in particular MSMEs, that lag further behind. Moreover, long quarantine periods for worker would promote investment in automation and robotics. Some high-tech companies have already increased their use of artificial intelligence tools to cope with the lack of workers due to quarantines.

- Personal data privacy will have to be reconsidered in order to manage the health crisis efficiently. The security of digital infrastructure (for example, to prevent health care facilities being hacked) becomes a matter of life or death.

The coronavirus will affect the quantity of jobs (increased unemployment and underemployment), the quality of work (reduced wages and access to social protection) and the most vulnerable groups, such as informal sector workers. 
- The International Labour Organization (ILO, 2020) estimates indicate a rise in global unemployment of between 5.3 million and 24.7 million people, from a base of 188 million unemployed in 2019. In a "mid" scenario, unemployment would increase by 13 million people.

- The loss of labour income will translate into lower consumption of goods and services, and could drive many workers into poverty.

- The crisis will have a disproportionate impact on the most vulnerable - people with underlying health conditions, older people, unemployed youth, underemployed people, women, unprotected workers and migrant workers-, with the knock-on effect of worsening inequality.

\section{B. Impact on Latin America and the Caribbean}

\section{Economic impact}

Latin America and the Caribbean is facing the pandemic from a weaker position than the rest of the world. Before the pandemic, ECLAC had projected that the region would grow by a maximum of $1.3 \%$ in 2020 . However, this forecast has been revised in light of the effects of the crisis, with GDP now predicted to fall by at least $1.8 \%$. Nevertheless, as the pandemic evolves, forecasts of economic contractions of between $3 \%$ and $4 \%$, or even more, cannot be ruled out. The final economic impact will depend on the actions taken at the national, regional and global levels.

- COVID-19 is affecting the region through five external transmission channels:

(i) The decline in the economic activity of the region's main trading partners and the effects of that. The region is heavily dependent on exports, the volume and value of which will be reduced by the global recession. The full extent of this will depend on the sectoral structure of each country.

(ii) The drop in commodity prices. The sharp falls in these prices and the deterioration in the terms of trade will have a strong negative impact on the income levels of the Latin American economies that depend on those exports, although with significant differences among them. The contraction in global demand, particularly from China, one of the largest consumers and importers of commodities, will play a major role in the decrease in commodity prices. In addition, a geopolitical crisis in the oil market led to a $24 \%$ reduction in prices in less than a week in early March 2020.

(iii) The interruption of global value chains. The disruption of supply chains, starting with Chinese suppliers followed by producers in Europe and the United States, would mainly affect Mexico and Brazil, whose manufacturing sectors are the largest in the region.

(iv) Lower demand for tourism services (see box 1). Caribbean small island developing States (SIDS), in particular, may be severely affected. If the greatest effects of COVID-19 are felt in the second quarter of 2020 and take the form of three-month travel bans or self-imposed travel restrictions, tourism in the Caribbean is expected to contract by $25 \%$.

(v) Greater risk aversion and worsening global financial conditions. This leads to higher demand for safe assets (for example, rates of return on United States securities have reached historically low levels), lower demand for the region's financial assets and a significant depreciation of its countries' currencies, as is currently the case. 


\section{Box 1 | Possible repercussions of COVID-19 on tourism in Latin America and the Caribbean}

Tourism has been one of the sectors most immediately affected by COVID-19 in the region. The impact has been particularly dramatic in the Caribbean, where, for several economies, tourism revenues accounted for more than $20 \%$ of GDP in 2018 (see figure 1).

Figure 1 | Latin America and the Caribbean: tourism revenues as a share of GDP, 2010 and 2018 (Percentages)

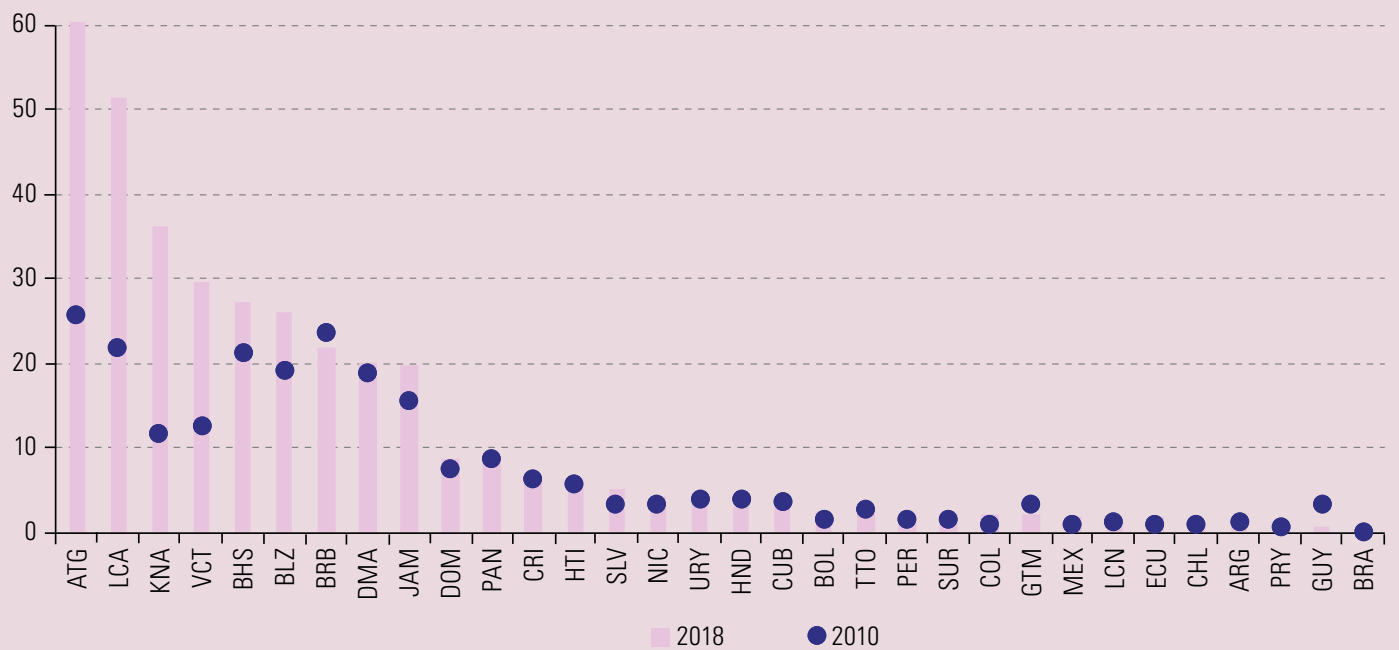

Source: Economic Commission for Latin America and the Caribbean (ECLAC).

In a scenario with a 10\% drop in tourism revenues in 2020, GDP would fall by $0.8,0.3$ and 0.1 percentage points in the Caribbean, Mexico and Central America, and South America, respectively. In a more negative scenario, in which tourism revenues decrease by $30 \%$ in 2020 , the drop for these subregions would be $2.5,0.8$ and 0.3 percentage points, respectively. The knock-on effects on employment, household incomes and government revenues would be greatest in the Caribbean, where the sector employs some 2.4 million people and accounts for $15.5 \%$ of GDP. The effects of the decline in tourism will be felt in particular by micro- and small enterprises, which carry enormous weight in the hotel and restaurant sector: accounting for $99 \%$ of enterprises and $77 \%$ of employment.

The full extent of the impact of COVID-19 on tourism will depend on the effects of the health and socioeconomic actions taken in the countries and regions from which most visitors come. For example, North America and Europe accounted for $69 \%$ and $17 \%$, respectively, of stay-over visitors in the Caribbean in 2018.

Source: Economic Commission for Latin America and the Caribbean (ECLAC).

The sectors most affected by social distancing and quarantine measures are the service sectors, which are largely dependent on interpersonal contact. In the region, the sectors that could suffer the greatest contractions - trade, transport, business services and social services-provide $64 \%$ of formal employment (see figure 3). In addition, 53\% of employment in the region is in informal activities, which will be severely affected as they rely on interpersonal contact to a large extent.

\section{Impact on international trade}

- The effects of COVID-19 are exacerbating the already weak foreign trade prospects for Latin America and the Caribbean. The "phase 1" trade agreement between the United States and China unveiled in January, under which China pledged to increase its imports of goods and services from the United States by at least US\$ 77 billion in 2020, ${ }^{1}$ threatens to displace Latin American and Caribbean exports to China in the same product categories. Considered in conjunction with the aforementioned sharp drop in oil prices, COVID-19 will lead to a contraction in international trade for the region, in terms of value and volume, through its direct impact on the region and through that on its trading partners.

See Reuters, "What's in the U.S.-China Phase 1 trade deal" [online] https://www.reuters.com/article/us-usa-trade-china-details-factbox/whats-in-the-us-china-phase-1trade-deal-idUSKBN1ZE2IF. 
Figure 3 | Latin America and the Caribbean: formal employment by sector of economic activity, 2018 (Percentages)

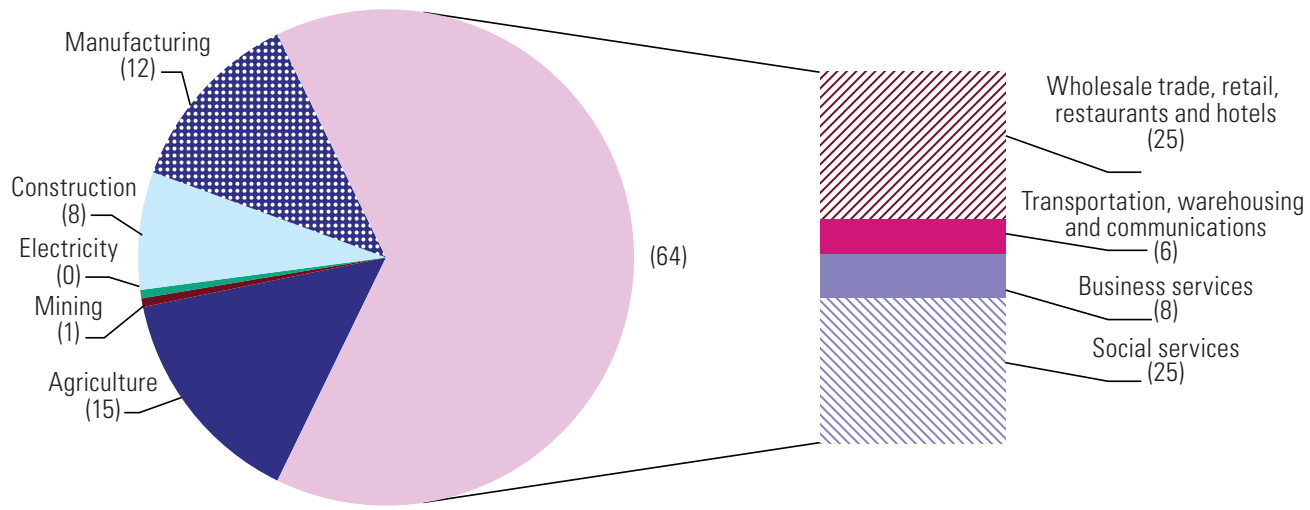

Source: Economic Commission for Latin America and the Caribbean (ECLAC).

Estimates of the impact of COVID-19 on the region's exports are set out in table 1. They assume different rates of GDP growth in the region's main trading partners and different price reductions in its exports. It is estimated that the value of the region's exports will fall by at least $\mathbf{1 0 . 7 \%}$ by 2020. Most of the reduction in export value is explained by the fall in their prices, estimated to be $8.2 \%$; in addition, export volume is expected to contract by $2.5 \%$.

Table 1 | Latin America and the Caribbean: impact of COVID-19 on goods exports by subregions and major exporting countries, forecast for 2020 (Percentage change)

\begin{tabular}{llcc}
\multirow{2}{*}{ Region/Subregion/Country } & \multicolumn{3}{c}{ Exports } \\
\cline { 2 - 4 } & Volume & Price & Value \\
\hline Latin America and the Caribbean & -2.5 & -8.2 & -10.7 \\
\hline Oil exporters & -1.8 & -14.1 & -15.9 \\
\hline Exporters of mining products & -3.0 & -8.9 & -12.0 \\
\hline Exorters of agro-industrial products & -2.4 & -2.5 & -5.0 \\
\hline South America & -2.8 & -11.0 & -13.8 \\
\hline Brazil & -3.7 & -7.5 & -11.2 \\
\hline Mexico & -2.2 & -5.2 & -7.4 \\
\hline Central America & -1.3 & -2.7 & -4.0 \\
\hline Caribbean countries & -2.0 & -7.2 & -9.3 \\
\hline
\end{tabular}

Source: Economic Commission for Latin America and the Caribbean (ECLAC)

Note: The following growth rates are assumed for 2020: 1.0\% (world), 1.0\% (United States), 0.3\% (Japan), 0.5\% (United Kingdom), -0.2\% (European Union, 27 countries), 3.0\% (China) and -1.8\% (Latin America and the Caribbean), plus an average reduction of 16\% in the region's commodity export basket.

At the subregional level, the greatest impact will be felt by the countries of South America, which specialize in the export of commodities and are therefore more vulnerable to a decline in their prices. In contrast, the value of exports from Central America, the Caribbean and Mexico would decrease less than average for the region, owing to their links with the United States and their limited exposure to falling commodity prices. Oil-exporting countries are expected to see the greatest drop in the value of foreign sales. Mexico, the Bolivarian Republic of Venezuela, Ecuador and Colombia may be hardest hit, as their production costs are higher than those of many other producers and they therefore have less capacity to withstand a prolonged period of low prices.

Regional exports to China are expected to fall the most in 2020 (-21.7\%) (see table 2). This would especially affect products with forward linkages in the value chains within China (iron ore, copper ore, zinc, aluminium, soybeans, soybean oil, among others). The most exposed countries are Argentina, Brazil, Chile and Peru, which are the region's largest suppliers of such products to China. 
Table 2 | Latin America and the Caribbean: impact of COVID-19 on goods exports to the world and selected trading partners, forecast for 2020 (Percentage change)

\begin{tabular}{lcl} 
Destination & Exports & Most affected sectors and countries \\
\hline World & -10.7 & \\
\hline China & -21.7 & $\begin{array}{l}\text { Agricultural products (Argentina, Brazil); } \\
\text { Mining (Chile and Peru) }\end{array}$ \\
\hline United States & -7.1 & Manufactures (Mexico, Costa Rica) \\
\hline European Union & -8.9 & $\begin{array}{l}\text { Mining (Chile, Colombia, Peru) Agricultural and } \\
\text { agro-industrial products (Argentina, Brazil, } \\
\text { Chile, Peru) }\end{array}$ \\
\hline Latin America and the Caribbean & -10.7 & Low- and medium-tech manufactures \\
\hline
\end{tabular}

Source: Economic Commission for Latin America and the Caribbean (ECLAC).

Note: The following growth rates are assumed for 2020: 1.0\% (world), 1.0\% (United States), 0.3\% (Japan), 0.5\% (United Kingdom), -0.2\% (European Union, 27 countries), 3.0\% (China) and -1.8\% (Latin America and the Caribbean), plus an average reduction of $16 \%$ in the region's commodity export basket.

- The COVID-19 crisis may also have an impact on the region's export performance because of its effect on imports used to produce exports. Mexico and Chile would be the countries most exposed to a drop in supply from China, which supplies about $7 \%$ of their intermediate inputs. They are followed by Colombia and Peru, which import $4.5 \%$ and $5 \%$ of their intermediate inputs from China, respectively. Mexico is the country most exposed to changes in supply and demand conditions in the United States, especially in the manufacturing sector. Costa Rica is also highly exposed to economic conditions in the United States, as about 10\% of its GDP depends on United States supply and demand. The countries most exposed to changes in supply and demand conditions in the European Union are Chile, Mexico and Brazil, as around $5 \%$ of their GDP depends on the value added of the service and manufacturing sectors in that bloc.

\section{Access to and use of the Internet}

- Measures to stop the spread of the coronavirus have accelerated the pace at which work and education are going digital. Digital technologies have lessened the impact of the pandemic on some professions and on education, while enabling personal communications and entertainment activities in the home.

Although more than $67 \%$ of the region's inhabitants were using the Internet by 2019 and broadband penetration has increased sharply, the greater use of digital technologies can exacerbate inequalities in access among countries and among income groups. While more than $80 \%$ of the population had a mobile Internet connection in Chile, Brazil, Costa Rica and Uruguay by 2017 , the figure dropped to $30 \%$ in Guatemala, Honduras, Haiti and Nicaragua (see figure 4).

Figure 4 | Latin America and the Caribbean: broadband penetration, 2017 (Percentages of the population)

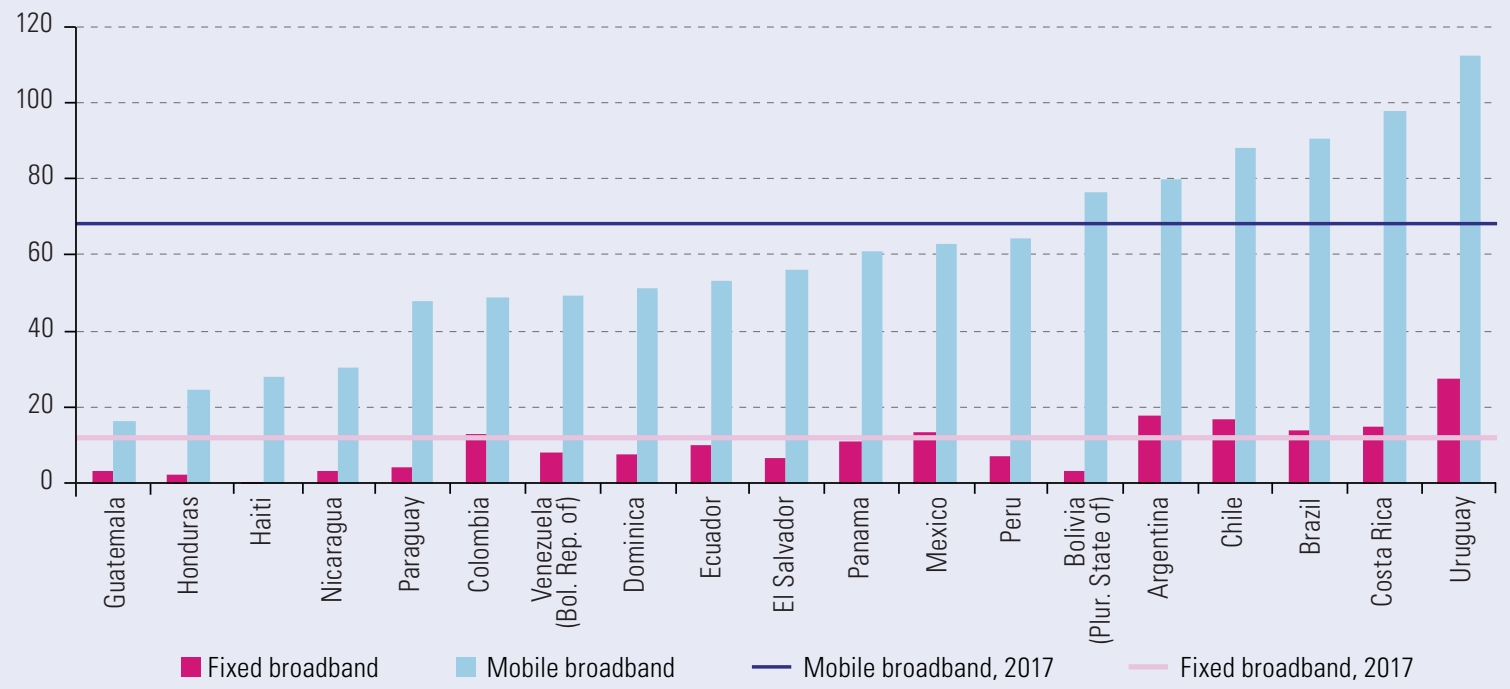

Source: Economic Commission for Latin America and the Caribbean (ECLAC), Regional Broadband Observatory (ORBA). 
- There are also marked inequalities in the connectivity rate among income segments. In Latin America and the Caribbean, the gap between the richest and poorest quintiles is widest in Honduras (58 percentage points) and Peru (60 percentage points), and narrowest in Chile (22 percentage points) and Uruguay (17 points).

Figure 5 | Latin America and the Caribbean: Internet users by income quintile, 2017 (Percentages)

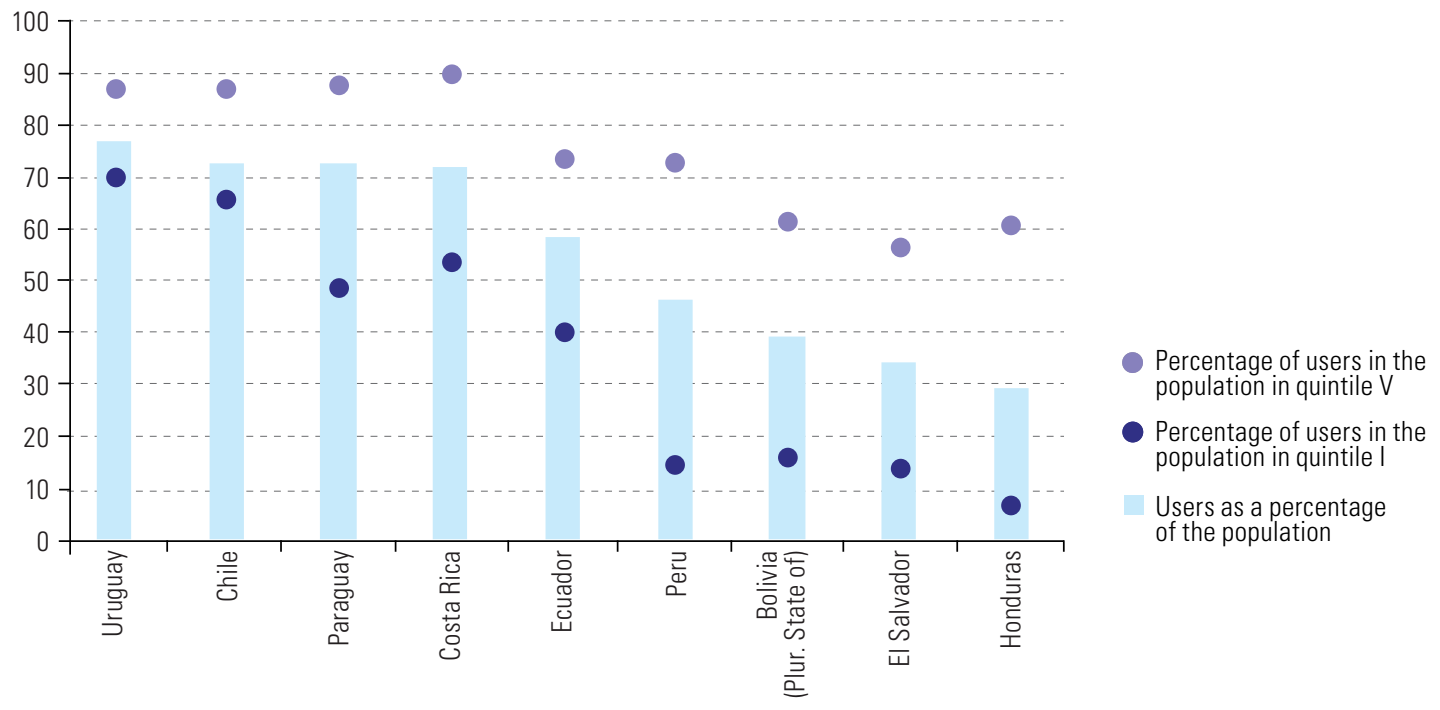

Source:Economic Commission for Latin America and the Caribbean (ECLAC), Regional Broadband Observatory (ORBA). Household Survey Database (BADEHOG), and Organization for Economic Cooperation and Development (OECD), OECD.Stat [online database] http://stats.oecd.org/.

\section{Social impacts}

Even before the COVID-19 pandemic, the social situation in Latin America and the Caribbean was deteriorating, as evidenced by the increasing rates of poverty and extreme poverty, the persistence of inequalities and widespread discontent. In that context, the crisis will have a negative impact on health and education, as well as on employment and poverty.

\section{Health systems}

- The impacts on the health sector will be profound owing to shortages of skilled labour and medical supplies, and to escalating costs. Most countries have underinvested in health. Central government spending on the sector, which in 2018 stood at 2.2\% of regional GDP (ECLAC, 2019; United Nations, 2020), is far from the 6\% of GDP recommended by the Pan American Health Organization (PAHO) to reduce inequities and increase financial protection within the framework of universal access to health and universal health coverage. Additional resources would help to strengthen the first level of care, with an emphasis on disease prevention (PAHO, 2019).

- Most countries of the region have weak and fragmented health systems, which do not guarantee the universal access needed to address the COVID-19 health crisis.

- In general, health systems are organized through public sector services for people with low incomes, social security services for formal workers and private services for those who can afford them. As a result, health systems remain segregated and patently unequal, providing different services of varying quality to different population groups. Although reforms have been undertaken to reduce fragmentation and expand access, health system are still inadequate.

- Moreover, health systems tend to be geographically centralized, with specialized services and physicians concentrated in a few urban centres.

- The facilities are insufficient for the level of expected demand and are heavily dependent on imports of equipment and inputs. This is a major problem because, as at 11 March 2020, 24 countries around the world had already restricted exports of medical equipment, medicines or their ingredients (The Economist, 2020). In 2018, only seven countries of the region had significantly more hospital beds per 1,000 people than the world average (see figure 6). 
Figure 6 | Latin America and the Caribbean: number of hospital beds per 1,000 people, 2018 or latest available data

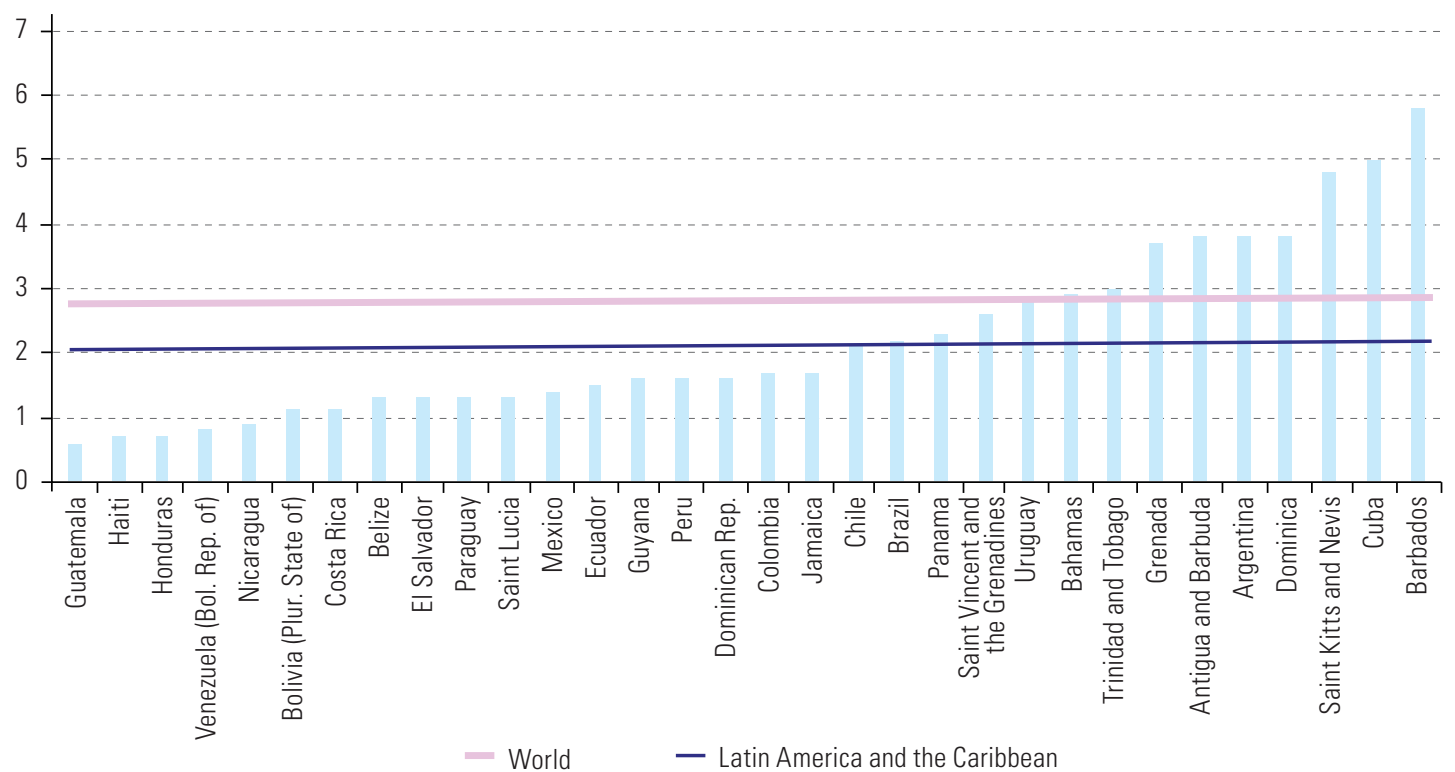

Source: Economic Commission for Latin America and the Caribbean (ECLAC), on the basis of Central Intelligence Agency (CIA), The World Factbook 2018 , Washington, D.C., and data of the Organization for Economic Cooperation and Development (OECD).

There are wide gaps in access to health systems. Participation in health insurance plans for employed people aged 15 years and older was only $57.3 \%$ in 2016 , and coverage was only $34.2 \%$ among the population in the lowest income decile. In addition, difficulties in accessing health facilities are acute in rural and remote areas.

- The health systems in several countries of the region were already under pressure from the dengue epidemic: there were more than 3 million cases of dengue in 2019 (the highest number ever recorded in the region to date), with 1,538 deaths attributed to the disease. Brazil had the highest number of cases: 2.2 million people (PAHO, 2020).

- The population covered by private health insurance could face high co-payments for access to coronavirus tests, which would be an obstacle to early detection. In 2016, out-of-pocket health expenditure by households as a proportion of total current health expenditure in Latin America and the Caribbean (37.6\%) was more than double that of the European Union (15.7\%) (WHO, 2017).

- As the demographic structure of the region is quite young, the overall impact may be less than in developed countries. On average, only $10 \%$ of the population of Latin America and the Caribbean (almost 58 million people) is aged 65 years or older. The health systems of countries with a population distribution more skewed towards older adults, such as Barbados, Cuba, Uruguay, Aruba and Chile, could be put under greater pressure.

\section{Education}

- As at 20 March 2020, Argentina, the Bolivarian Republic of Venezuela, Chile, Colombia, Ecuador, El Salvador, Guatemala, Honduras, Jamaica, Panama, Paraguay, Peru, the Plurinational State of Bolivia, Saint Lucia, Trinidad and Tobago, and Uruguay had suspended classes at all levels of education. Localized school closures have been implemented in Brazil.

- Disruption of activities in educational establishments will have a significant impact on learning, especially for the most vulnerable.

- Educational establishments also provide many children with food security and care, allowing parents time to work. Suspending classes will have an impact beyond education, affecting nutrition, care and parents' (especially women's) participation in the labour market. 
- Some 85 million children in the region are given breakfast, a snack or lunch at school (FAO/WFP, 2019). It is therefore important to ensure the continuity of school feeding programmes.

- Although plans have been made to promote the use of digital devices in educational systems, many educational establishments do not have the necessary digital technology infrastructure. In addition, there are gaps in access to computers and the Internet among households. Distance learning and teaching processes are not guaranteed.

- Moreover, there are disparities in access to digital devices and broadband Internet between urban and rural populations, between the sexes, between populations that speak the official language (Spanish or Portuguese) and those that do not, and between populations with and without disabilities.

- Latin America faces challenges with regard to training teachers on information and communications technology (ICT). For example, only 20\% of teachers in Brazil in 2018 had participated in a continuing education course on the use of computers and the Internet for teaching. In terms of Internet use, $16 \%$ of teachers reported using it one or more times a day; while $20 \%$ used it once a week, and 18\% used it at least once a month (Brazilian Internet Steering Committee, 2019).

\section{Employment and poverty}

- Given the region's economic and social inequalities, the strong unemployment effects will disproportionately impact the poor and vulnerable middle-income strata.

- The crisis is likely to lead to an increase in informal employment as a survival strategy. In 2016, $53.1 \%$ of workers in Latin America and the Caribbean were in the informal sector (ILO, 2018).

- The poorest families may send their children into the labour market, pushing up child labour rates. According to ILO estimates, $7.3 \%$ of children aged from 5 to 17 years (some 10.5 million children) in the region work.

- ECLAC (2019) showed that poverty in the region increased between 2014 and 2018 (ECLAC, 2019). As a result of the direct and indirect effects of the pandemic, it is highly likely that the current rates of extreme poverty $(11.0 \%)$ and poverty $(30.3 \%)$ will increase even more in the short term.

- If the effects of COVID-19 lead the economically active population to lose $5 \%$ of their income, poverty could increase by 3.5 percentage points, while extreme poverty is expected to rise by 2.3 percentage points (see table 3). Sharper drops in income will mean even greater increases in poverty rates.

Table 3 | Latin America (18 countries): poverty and extreme poverty with a 5\% drop in the income of the economically active population in 2020, 2019-2020a

(Number of people and percentages)

\begin{tabular}{lrr} 
& 2019 & 2020 \\
\hline Population & 613476000 & 619205000 \\
\hline Poverty & & \\
\hline Number of persons living in poverty & 185944000 & 209583000 \\
\hline Absolute change & 3464000 & 23595000 \\
\hline Rate (percentages) & 30.3 & 33.8 \\
\hline Percentage points per year & 0.3 & 3.5 \\
\hline Extreme poverty & 67487000 & 15119000 \\
\hline Number of persons living in extreme poverty & 4774000 & 13.3 \\
\hline Absolute change & 11.0 & 2.3 \\
\hline Rate (percentages)
\end{tabular}

Source: Economic Commission for Latin America and the Caribbean (ECLAC).

a $\mathrm{A} \%$ drop in income is assumed for the economically active population in 2020. 
Economic impact on micro-, small and medium-sized enterprises

- Almost $\mathbf{9 9 \%}$ of Latin American companies are micro-, small or medium-sized enterprises (MSMEs), and they make up the majority of companies in almost all economic sectors.

- People employed by MSMEs are very vulnerable to the pandemic crisis. The temporary shutdown of economic activities and preventive quarantine measures will lead to a significant reduction in revenue. Sales could be insufficient for the survival of these companies, which would be unable to pay salaries, employee contributions and social security contributions, and could even go bankrupt.

The economic impact on MSMEs will have a high social cost, as micro- and small enterprises accounted for $\mathbf{4 7 . 1 \%}$ of total employment in $\mathbf{2 0 1 6}$, rising to $61.1 \%$ if medium-sized enterprises are included (Dini and Stumpo, 2019).

\section{Social protection}

- Social protection in Latin America and the Caribbean was already inadequate before the COVID-19 outbreak. The crisis will put additional pressure on countries with limited fiscal space, endangering social spending, which is already strained after seven years of sluggish economic growth.

- Four sets of issues related to social protection systems in the region that may affect the severity of the pandemic's consequences in this field are discussed below.

- High rates of informality, increased self-employment and gaps in access to contributory social protection.

- Few countries have unemployment benefits; in 2019, only in Argentina, Brazil, Chile, Colombia, Ecuador and Uruguay did formal sector workers have unemployment insurance.

- Contributory social protection systems will be affected financially by higher demand for sick leave benefits by formal sector workers.

- Tax-funded non-contributory social protection programmes support the poorest; they will need to be extended to other low-income families at risk of falling into poverty

- The health crisis highlights the unjust social organization of care in the region, where it is considered an externality rather than a fundamental component of development. Responses to care needs must be considered from a gender perspective because it is women who, whether paid or unpaid, bear the greatest caregiving burden.

- As at 23 March 2020, some 154 million children and adolescents (more than 95\% of those enrolled in education in the region) were temporarily out of school due to the COVID-19 (UNICEF, 2020). These children require care that overburdens families' time, particularly that of women, who spend three times as long as men on unpaid domestic and care work each day. Moreover, gender inequalities are sharper in lower-income households, where the demands for care are greater, as they tend to have more dependents per household.

- Women are also particularly affected by the pressure on health systems because they make up $72.8 \%$ of the total number of people employed in the sector in the region. ${ }^{2}$ The greater demand has resulted in extreme working conditions, such as long working days without being able to rest or stop to eat or use the toilet, which increase health personnel's risk of being infected by the virus. At the same time, women working in this sector are still responsible for dependants or people in need of care within their households. They must continue to go to work in addition to this responsibility, which increases their excess workload and stress.

\section{Social cohesion}

- The economic and social circumstances outlined above are unfolding in a context of widespread political instability or outright political upheaval. Confidence in political institutions (parliament, the executive, the judiciary and political parties) is at its lowest level in decades. The loss of confidence in democracy will be even more serious if governments fail to provide an adequate

Data collected through the processing of household surveys of 16 countries around 2017 available in the Household Survey Data Bank (BADEHOG) of ECLAC. 
response to COVID-19. This will compound a deepening geopolitical crisis and the redistribution of economic, political and military power among the leading nations.

- At the national level, the resurgence of extreme right-wing and isolationist parties is the result of a loss of confidence in multilateral institutions and strategic integration projects, such as the European Union or multiregional trade agreements.

- Racism and xenophobia are another expression of this process. Governments at both national and local levels are restricting the movement of people across borders.

\section{Policy recommendations}

1. A commensurate fiscal stimulus is needed to support health services and protect incomes and jobs. The uninterrupted supply of essential goods, in particular pharmaceuticals, medical equipment, food and energy, must be guaranteed. Universal access to testing and care must be ensured for all who need it. Although some countries have limited fiscal space, health spending is now a priority, especially in countries with weak and fragmented health-care systems.

2. Social protection systems need to be strengthened to support vulnerable populations. Non-contributory programmes, such as direct cash transfers to the most vulnerable, unemployment, underemployment and self-employment benefits, interest-free loans to firms to allow them to pay wages, and loan payment deferrals, should be expanded. Immediate support should be provided to workers in MSMEs, low-income workers and those in the informal sector. Mortgage and rent payment deferrals and other exemptions are crucial to avoiding a housing crisis and business foreclosures. Measures such as deferring payment of water, electricity and Internet bills for low-income people for the duration of the pandemic should be considered.

3. Central banks must ensure firms' liquidity to ensure their operations can be carried out and the stability of the financial system. Expansive monetary policies will not be enough; central banks should intervene directly to provide the liquidity needed by the financial and non-financial private sectors, in particular to ensure full liquidity in the overnight bank lending market and to avoid disruption of payment chains.

4. International cooperation and multilateral organizations should design new technical and financial instruments to support countries facing fiscal pressures. They should also consider offering low-interest loans and debt relief and deferrals to open up the fiscal space. Developed and developing countries have different means available to them to cope with this unprecedented crisis, which may exacerbate international inequalities. Some heavily indebted countries, such as some Caribbean islands or Argentina, may have problems servicing, restructuring or increasing their debts because of the possible collapse of financial markets, which would undermine the much-needed public spending on health, social protection and economic stimulus. Countries must tailor their responses to local conditions, which should be strengthened by international cooperation.

5. Lift the sanctions on countries that are subject to them so they can have access to food, medical assistance and supplies, and COVID-19 tests. This is a time for solidarity, not exclusion.

The COVID-19 outbreak came at a time when the global economy was slowing down. Debt levels were historically high, and wages and productivity had stagnated in many developing and developed countries. The health crisis has exposed the fragility of the globalized system and the underlying development model. The breakdown of supply chains, the slowdown in global growth and the performance of financial markets have shown that economies are exposed to global vulnerabilities. After this crisis, the global community will have to face the fact that globalization has not worked as it was supposed to and that it needs to be reformed extensively. Thus, the decoupling of financial markets and real economy flows must be contained and regulated. Furthermore, it must be recognized that international trade is not, in itself, a driver of long-term growth: it must be pursued in tandem with industrial policies that foster diversification towards more sophisticated industries. The inequalities among countries and among social groups that have increased the fragility of the global system must be addressed once and for all. 
Ultimately, the only sustainable solution to the socioeconomic challenges arising from the COVID-19 pandemic will be the coordinated containment of the virus. The scale, speed and extent of its spread requires greater multilateral policy coordination. This pandemic has the potential to reshape the geopolitics of globalization, and it is also an opportunity to recall the benefits of multilateral action and to start much-needed action on a sustainable and inclusive development model.

\section{Bibliography}

Brazilian Internet Steering Committee (2019), Survey on the use of information and communication technologies in Brazilian schools: ICT in education 2018, São Paulo.

Dini, M. and G. Stumpo (coords.) (2019), "Mipymes en América Latina: un frágil desempeño y nuevos desafíos para las políticas de fomento. Síntesis", Project Documents (LC/TS.2019/20), Santiago, Economic Commission for Latin America and the Caribbean (ECLAC).

ECLAC (Economic Commission for Latin America and the Caribbean) (2019), Social Panorama of Latin America, 2019 (LC/PUB.2019/22-P/Rev.1), Santiago.

FAOMFP (Food and Agriculture Organization of the United Nations/World Food Programme) (2019), Strengthening School Feeding Programmes: FAO and WFP Joint Work in Latin America and the Caribbean, Panama City.

Goldman Sachs (2020), "Roaring into recession", Top of Mind, No. 87, 24 March.

ILO (International Labour Organization) (2020), "COVID-19 and the world of work: impact and policy responses", 18 March [online] https://www.ilo.org/wcmsp5/groups/public/-dgreports/-dcomm/documents/ briefingnote/wcms_738753.pdf.

_ (2018), Women and Men in the Informal Economy: A Statistical Picture, third edition, Geneva.

PAHO (PanAmerican Health Organization) (2020), "Epidemiological update: dengue,"7 February [online] https://iris. paho.org/bitstream/handle/10665.2/51892/EpiUpdate7February2020_eng. pdf? sequence=1 \&isAllowed=y.

_ (2019), Core Indicators 2019: Health Trends in the Americas, Washington, D.C.

The Economist (2020), "New trade barriers could hamper the supply of masks and medicines" 11 March [online] https://www.economist.com/finance-and-economics/2020/03/11/new-trade-barriers-could-hamperthe-supply-of-masks-and-medicines.

UNICEF (United Nations Children's Fund) (2020), "COVID-19: more than 95 per cent of children are out of school in Latin America and the Caribbean", 23 March [online] https://www.unicef.org/press-releases/ covid-19-more-95-cent-children-are-out-school-latin-america-and-caribbean.

United Nations (2020), SDG indicators [online] https://unstats.un.org/sdgs/indicators/database/.

WHO (World Health Organization) (2017), Global Health Expenditure [online database] https://apps.who. int/nha/database/Select/Indicators/en.

This Special Report is the first in a series by the Economic Commission for Latin America and the Caribbean (ECLAC) on the evolution and impacts of the COVID-19 pandemic in Latin America and the Caribbean, and will update the economic and social analysis as the relevant information becomes available. The preparation of the Report will be headed by the Executive Secretary of ECLAC, Alicia Bárcena, with the technical support of the Office of the Deputy Executive Secretary, Mario Cimoli, and the substantive divisions responsible for the topics addressed, as well as the subregional headquarters and country offices of ECLAC.

Copyright (C) United Nations, 2020 